\title{
THE PHYSICAL PROPERTIES OF CAST STONE
}

\author{
By John Tucker, jr., G. W. Walker, and J. Arthur Swenson
}

\section{ABSTRACT}

The paper is a report of the results of tests made as a basis for the preparation of a Federal specification for cast stone. Samples representative of all the usual methods of fabrication, including a wide variety of aggregates, were studied. The compressive strengths varied from 1,550 to $21,720 \mathrm{lbs}$./in. ${ }^{2}$ and the 48 hours absorption varied from 2.0 to 13.1 per cent. The resistance of the material to freezing and thawing varied from complete destruction of the least resistant specimen in the twenty-fifth cycle to the most resistant specimen that first showed signs of disintegration at the one thousand four hundred and fiftieth cycle. Correlation between the resistance to freezing and the other physical properties was very poor. As a specification requirement the Schurecht ratio was the most valuable. Specimens that had an absorption greater than 6 per cent after five hours boiling were usually of poor quality if the Schurecht ratio was greater than 0.9 or less than 0.6. The Schurecht criterion is based upon a theoretical upper limit of 0.9 , but the assignment of a lower limit is purely empirical.

It is shown that the specification drawn for cast stone assures that any sample accepted will very probably be of good quality.

\section{CONTENTS}

I. Introduction

II. Source of the samples.

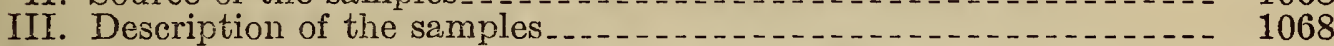

IV. Preparation of test specimens

V. Tests _...... 1069

1. Sírength tests

2. Absorption and porosity tests.

3. Freezing and thawing tests

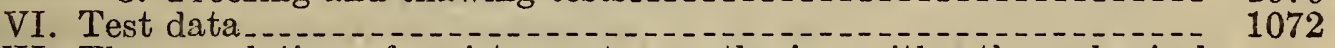

VII. The correlation of resistance to weathering with other physical properties. . .

VIII. Specification requirements. 1080

IX. Summary

$\mathrm{X}$. Acknowledgment

\section{INTRODUCTION}

The present study of cast stone was undertaken to obtain data from which a specification could be prepared for the Federal Specifications Board. Moreover, published data on the physical properties of cast, stone at the time the tests were begun were very meager, and the producers and users of this material had indicated that a knowledge of the properties would be of considerable interest to them.

The essential requirements for a cast stone are appearance, freedom from discoloration, and durability when exposed to weathering. Strength is relatively unimportant, and it may safely be assumed that if the material will resist disintegration by weathering action, it will be sufficiently strong for all other requirements. The appearance or texture is a matter of concern to the architect and may be covered by a statement to that purport in the specifications. The most serious discoloration is that due to efflorescence. This could be controlled far more effectively in cast stone, it is believed, by the prevention of 
moisture penetration through the wall and the use of proper mortars than by an attempt to reduce the efflorescence by properties of the cast stone itself.

The weathering properties of a concrete may be, it is now currently believed, most accurately determined by freezing and thawing cycles repeated until disintegration occurs. Such tests, however, require a very long time for completion. It is desirable then to deternine if a correlation exist between such resistance to disintegration and the results of tests that can readily be made within a short time in the laboratory, such as compressive strengths and absorptions. These physical properties were measured principally with the object of obtaining such a correlation.

The detailed data and description of test methods are being published in the 1932 Proceedings of the American Concrete Institute, volume 28.

\section{SOURCE OF THE SAMPLES}

A number of manufacturer's samples submitted to Federal departments were given to the bureau for tests, and in addition a number of manufacturers supplied samples upon request. Several samples were selected directly upon the building site by bureau representatives. The greater part of the samples was secured through the cooperation of C. G. Walker, secretary of the Cast Stone Institute.

\section{DESCRIPTION OF THE SAMPLES}

The samples tested included specimens made by the wet cast, dry tamped, puddled, and vibrated processes and of the faced and homogeneous types. The surface textures and colors of the samples varied over a wide range. Calcite, chiefiy in the form of marble, was one of the most extensively used in a considerable variety of aggregates. Data were submitted by some of the manufacturers on the properties, material, method of casting, and curing conditions for a portion of the samples, but no direct data concerning the fabrication of the stone was obtained by the bureau.

\section{PREPARATION OF TEST SPECIMENS}

One or more pieces slightly over 2 inches thick were cut from the samples. From these pieces six 2 by 2 inch cylinders were cored perpendicular to the face. The ends of three of the cylinders for the compression tests were ground until they were $2 \pm 0.06$ inches in height and finished to flat plane surfaces perpendicular to the axis. The three cores to be used in the freezing and thawing tests were so finished that no projections remained on any of the surfaces.

Three or more bars, approximately 1 by 1 by 8 inches in size, intended for the cross bending and the absorption tests, were cut from the samples and hand finished on the grinding lap.

Two-inch by two-inch prisms 4 inches long were also cut from a, number of samples for modulus of elasticity determinations. 
V. TESTS

\section{STRENGTH TESTS}

The samples were air-dry when received, but in cutting and grinding the test specimens to size they absorbed considerable water. 1 dry condition was selected as preferable to a saturated condition for test purposes because of cleanliness in handling specimens and the probable saving in time. The cylinders and bars for the strength tests were, therefore, dried for 72 hours at a temperature of $105^{\circ}$ to $110^{\circ} \mathrm{C}$. They were then immediately stored over calcium chloride in a desiccator at room temperature until tested.

Compressive tests were made on three 2-inch diameter cylinders cut from each sample. The 2 by 2 inch cylinder rather than a 2 by 4 inch cylinder was used because natural stone is usually tested in the form of 2-inch cylinders and because it was desired to include proportionately as much of the facing material as possible in the test specimen. The cylinders from faced cast stone were cut perpendicular to the face, and included all the facing and some of the backing. None of the specimens was capped nor was any material placed between the specimen and the upper or the lower bearing.

The cross bending specimens were tested by loading the midpoint of a 6 -inch span, at the rate of 140 pounds per minute. The modulus of rupture was computed by the usual equation.

Three of the halves remaining after the modulus of rupture tests were cut to 2 inches in height within a tolerance of one-sixteenth inch, and the ends finished to flat surfaces perpendicular to the axis of the prism. These specimens were dried for 72 hours in an oven maintained between $105^{\circ}$ and $110^{\circ} \mathrm{C}$., then stored in the desiccator, and tested in compression with the axis of the prism perpendicular to the platen. The prisms were tested in addition to the cores, in order to determine the relative merits of the two forms of specimens for the purposes outlined in the introduction.

In addition, 2 by 2 inch prisms 4 inches long cut from a number of samples were used for the determination of the stress-strain relation. The strains were measured by two Tuckerman strain gages of 2 -inch span mounted on opposite faces. The gages were attached to the prisms with elastic bands and rested on one-quarter by threequarter inch rectangles of sheet aluminum fastened to the specimen with De Khotinsky cement.

\section{ABSORPTION AND POROSITY TESTS}

Three of the halves of the bars remaining after the cross-bending test were ground until they were approximately 3 inches long. These were dried at $105^{\circ}$ to $110^{\circ} \mathrm{C}$. until the loss in weight in 24 hours was not more than 0.1 per cent, then stored in the desiccator and the absorption determined after they had attained room temperature, by total immersion in distilled water maintained at room temperature. At the end of one-half hour, 2, 4, 6, 24, and 48 hours, the pieces were removed from the water, wiped with a damp towel, and weighed. The weight of water absorbed was assumed to be the difference between the wet weight and the dry weight.

After the 48-hour absorption period the specimens were kept in boiling water for five hours. Cold water was then run into the vessel 
until room temperature was attained. The specimens were then wiped with a damp cloth and weighed. Afterwards they were weighed suspended in water. The total volume of water that had been absorbed when the specimens were boiled was taken as a rough measure of the total pore space, or porosity, and was computed by the equation:

$$
P=100 \frac{W_{b}-W_{a}}{W_{b}-W_{w}}
$$

where

$P=$ apparent porosity, per cent.

$W_{b}=$ weight of specimens after boiling.

$W_{d}=$ weight of specimen when dry.

$W_{w}=$ weight of saturated specimen suspended in water.

From most of the samples three more 1 by 1 by 3 inch prisms were cut for further absorption tests. These were dried in an electrically heated oven maintained at $65^{\circ} \mathrm{C}$. through which a current of air, dried by passage through sulfuric acid, was passed. The drying was continued until the loss in weight during a 24 -hour period was less than 0.1 per cent. The specimens were then immersed in water at $21^{\circ} \mathrm{C}$., and the water boiled for five hours. Cool water was then injected into the boiler until room temperature was attained. The prisms were then removed one by one, the excess water wiped off with a damp towel, and the specimens immediately weighed. Following this, they were again placed in the $65^{\circ}$ drying oven until the loss in weight was less than 0.1 per cent in 24 hours.

From each of 12 representative samples, three more 2 by 2 inch cores were cut. These specimens were placed in water at $21^{\circ} \mathrm{C}$. for 24 hours and then placed in an electric-heated oven maintained at $35^{\circ} \mathrm{C}$., through which a current of dry air passed. The drying was continued until the loss in weight of the specimens during a 24-hour period was less than 0.1 per cent. The specimens were then immersed in $300^{\circ} \mathrm{F}$. oil (that used in railway signal lamps) maintained at $21^{\circ} \mathrm{C}$. and the rate of absorption was obtained over a period of 48 hours. After this the specimens, while totally immersed in oil, were subjected to the reduced pressure of about $3 \mathrm{~mm}$. of mercury absolute for five hours. The absorption was computed in terms of equivalent water absorption; that is, the weight of oil absorbed was divided by the specific gravity of the oil, thus giving the weight of water that would occupy the same space in the specimens that the absorbed oil occupied.

The use of these methods of drying at $35^{\circ}$ or $65^{\circ}$ in the process of determining the absorption was an effort to reduce or eliminate the loss of water of hydration of the cement that might occur through drying above the boiling point of water, to reduce or eliminate the consequent possible further hydration of the cement and also to reduce or eliminate the leaching out of some of the hydration products that might occur during the boiling in water. Any difference in the weight of water lost through drying at $35^{\circ}$ or $65^{\circ} \mathrm{C}$. and that lost through drying at $105^{\circ} \mathrm{C}$. may be termed water of hydration.

\section{FREEZING AND THAWING TESTS}

The 2 by 2 inch cylindrical specimens prepared for the freezing and thawing tests were first immersed in water at approximately $20^{\circ} \mathrm{C}$. for 48 hours. They were then started on cycles of alternate 
freezing in an atmosphere maintained at $-12^{\circ}$ to $-15^{\circ} \mathrm{C}$. and thawing in a tank of water at room temperature. The specimens were invariably standing in one-fourth inch of water when placed in the freezing chamber so that the loss by evaporation from the surface of the specimen into the dry air of the chamber might be replaced by capillary rise from the water in the tray.

The specimens were examined at frequent intervals, particularly up to the first 100 cycles. Four states of disintegration were recorded:

First stage. - The number of the cycle at which the first sign of disintegration was noted.

Second stage.-The number of the cycle when the disintegration had progressed to the extent that an area equal to $1 \mathrm{~cm}^{2}$ had spalled from the specimen.

Third stage.-The number of the cycle when the condition was such that the value of the stone for facing would be utterly destroyed.

Fourth stage.-The number of the cycle when at least one-third of the specimen was destroyed, or when the strength had been so reduced that complete disintegration would have occurred within a few more cycles.

Some specimens (which had previously not shown any signs of disintegration) developed such severe failure during a single cycle as to warrant them being classed in the second or third stages. In such cases the arrival of the first and second (or third) stages is represented by the same number of cycles.

The measurement of the disintegration by such a method is governed solely by the judgment of the observer, and is open to the objection that two observers might disagree as to the exact number of cycles at which any one specimen should be advanced from one stage to the next. Another method of measuring the disintegration would be to weigh the specimens and advance them from stage to stage according to loss in weight. This latter method, however, has the very serious disadvantage of giving no weight to the appearance of the stone nor the kind of disintegration. For example, a surface layer of one-eighth inch in thickness might come from off a sample of cast stone, leaving the fresh surface practically as satisfactory in appearance as the original surface, whereas the surface of another stone might pit and present a very poor appearance with the loss of much less material. As another illustration, one sample cracked into two pieces. By the weight criterion this would have been a large loss, yet in a building, if the crack occurred in a direction almost perpendicular to the face, the appearance and utility of the piece would not be appreciably affected.

The number of cycles at which the first signs of disintegration occurred were capable of closer measurement and, therefore, were more accurately determined than for the succeeding stages. Since these first signs of disintegration were most accurately determined it may appear wasteful of time and energy to have continued the tests beyond this point. The amount of disintegration that was first observed, however, was usually so small that the value of the stone was practically unchanged. It was therefore necessary to continue the tests until appreciable disintegration occurred, in order to obtain data that would be of value in showing the relative resistance of the various samples up to the point where the value of the 
material as facing for building had been largely destroyed by the freezing and thawing tests. An arbitrary combination of the number of cycles for each of the four stages was used as a means of comparing the resistance of the samples to disintegration. For convenience this is called the mean resistance, and is computed as follows:

Where

$$
\text { Mean resistance }=A+0.95(B-A)+0.50(C-B)
$$

$A$ is the number of cycles when the first stage is reached.

$B$ is the number of cycles when the second stage is reached.

$C$ is the number of cycles when the third stage is reached.

\section{TEST DATA}

Since not more than three tests were made for the determination of each property, reliable information could not be gained as to the relative accuracy with which test results could be repeated for the different samples. However, an estimated modulus of precision for each type of test determination has been given in Table 1 .

To show the distribution of the values of the more important test measurements the histograms of Figures 1 to 4 have been prepared. The averages of the tests of all specimens from each sample, and not the individual test results, were used in preparing these figures.

TABLE 1.-Precision measures

\begin{tabular}{|c|c|c|c|c|c|c|c|}
\hline 8 & \multicolumn{2}{|c|}{$\begin{array}{l}\text { Compressive } \\
\text { strength }\end{array}$} & \multirow[b]{2}{*}{$\begin{array}{c}\text { Modulus } \\
\text { of } \\
\text { rupture }\end{array}$} & \multicolumn{3}{|c|}{$\begin{array}{l}\text { Water absorption (in per cent } \\
\text { of dry weight) }\end{array}$} & \multirow[b]{2}{*}{$\begin{array}{l}\text { Schurecht } \\
\text { ratio }\end{array}$} \\
\hline & $\begin{array}{c}2 \text { by } 2 \\
\text { inch } \\
\text { cylinders }\end{array}$ & $\begin{array}{c}1 \text { by } 1 \text { by } \\
2 \text { inch } \\
\text { prisms }\end{array}$ & & $\begin{array}{l}48 \text { hours } \\
\text { at room } \\
\text { temper- } \\
\text { ature }\end{array}$ & $\begin{array}{l}49 \text { hours } \\
\text { plus } 5 \\
\text { hours } \\
\text { boiling }\end{array}$ & $\begin{array}{l}5 \text { hours } \\
\text { boiling } \\
\text { after } \\
65^{\circ} \mathrm{C} \text {. } \\
\text { drying }\end{array}$ & \\
\hline $\begin{array}{l}\text { Minimum } \\
\text { Maximum } \\
\text { Standard deviation }{ }^{2}(\sigma) \\
\text { Coefficient of variation } 2(\mathrm{CV})\end{array}$ & $\begin{array}{r}\text { Lbs.jin. }{ }^{2} \\
1,550 \\
21,720\end{array}$ & $\begin{array}{r}\text { Lbs./in. }{ }^{2} \\
1,300 \\
15,780\end{array}$ & $\begin{array}{r}\text { Lbs./in. }{ }^{2} \\
220 \\
1,640\end{array}$ & $\begin{array}{r}2.0 \\
13.1\end{array}$ & $\begin{array}{r}2.5 \\
18.2\end{array}$ & $\begin{array}{r}3.0 \\
17.2\end{array}$ & $\begin{array}{r}0.39 \\
1.00 \\
.08\end{array}$ \\
\hline \multirow[b]{2}{*}{ t } & \multirow[b]{2}{*}{ Porosity } & \multirow[b]{2}{*}{$\begin{array}{c}\text { Apparent } \\
\text { specific } \\
\text { gravity }\end{array}$} & \multicolumn{3}{|c|}{$\begin{array}{c}300^{\circ} \text { oil absorption (in per cent } \\
\text { of dry weight) }\end{array}$} & \multicolumn{2}{|c|}{$\begin{array}{l}\text { Resistance to dis- } \\
\text { integration }\end{array}$} \\
\hline & & & $1 / 2$ hour & 48 hours & $\begin{array}{l}48 \text { hours } \\
\text { plus } 5 \\
\text { hours } \\
\text { vacuum }\end{array}$ & $\begin{array}{l}\text { Final } \\
\text { stage }\end{array}$ & $\begin{array}{l}\text { Mean } \\
\text { resistance }\end{array}$ \\
\hline $\begin{array}{l}\text { Minimum } \\
\text { Maximum } \\
\text { Coefficient of variation }{ }^{2}(\mathrm{Cv})\end{array}$ & $\begin{array}{r}\text { Per cent } \\
6.7 \\
32.7\end{array}$ & $\begin{array}{l}1.80 \\
2.66\end{array}$ & $\begin{array}{l}0.4 \\
8.4\end{array}$ & $\begin{array}{l}1.6 \\
9.2\end{array}$ & $\begin{array}{r}2.4 \\
13.4\end{array}$ & $\begin{array}{r}\text { Cycles } \\
25 \\
1(1,730) \\
30\end{array}$ & $\begin{array}{l}\text { Cycles } \\
2 \tilde{j} \\
1(1,545)\end{array}$ \\
\hline
\end{tabular}

1 At the number of cycles indicated the samples had not reached the inal stage. That with 1,545 cycles had not reached the second stage.

\& Whichever constant shows least variation through the range from low to high, has been given. The parameters are for iudividual specimens; for porosity they have been computed from the precision of the measurements from which the porosity was computed. 
The prism strengths varied from 1,300 to $15,780 \mathrm{lbs} . / \mathrm{in} .^{2}$ The higher values are considerably more than the strengths ordinarily obtained in concrete, strengths of the latter greater than 6,000 lbs./in. ${ }^{2}$ being rare. Concrete specimens, however, are ordinarily tested in a moist condition, whereas the strength tests in the present case were made upon well-dried specimens. The samples with strengths above $12,000 \mathrm{lbs}$./in. ${ }^{2}$ according to the manufacturer, were molded by the vibration process and were then steam cured. The strength of one sample, $15,780 \mathrm{lbs} . / \mathrm{in}^{2}{ }^{2}$ is extremely high for concrete of as lean a mix as the appearance of the sample would indicate. The cylinder strengths, as was to be expected from the difference in ratio of height

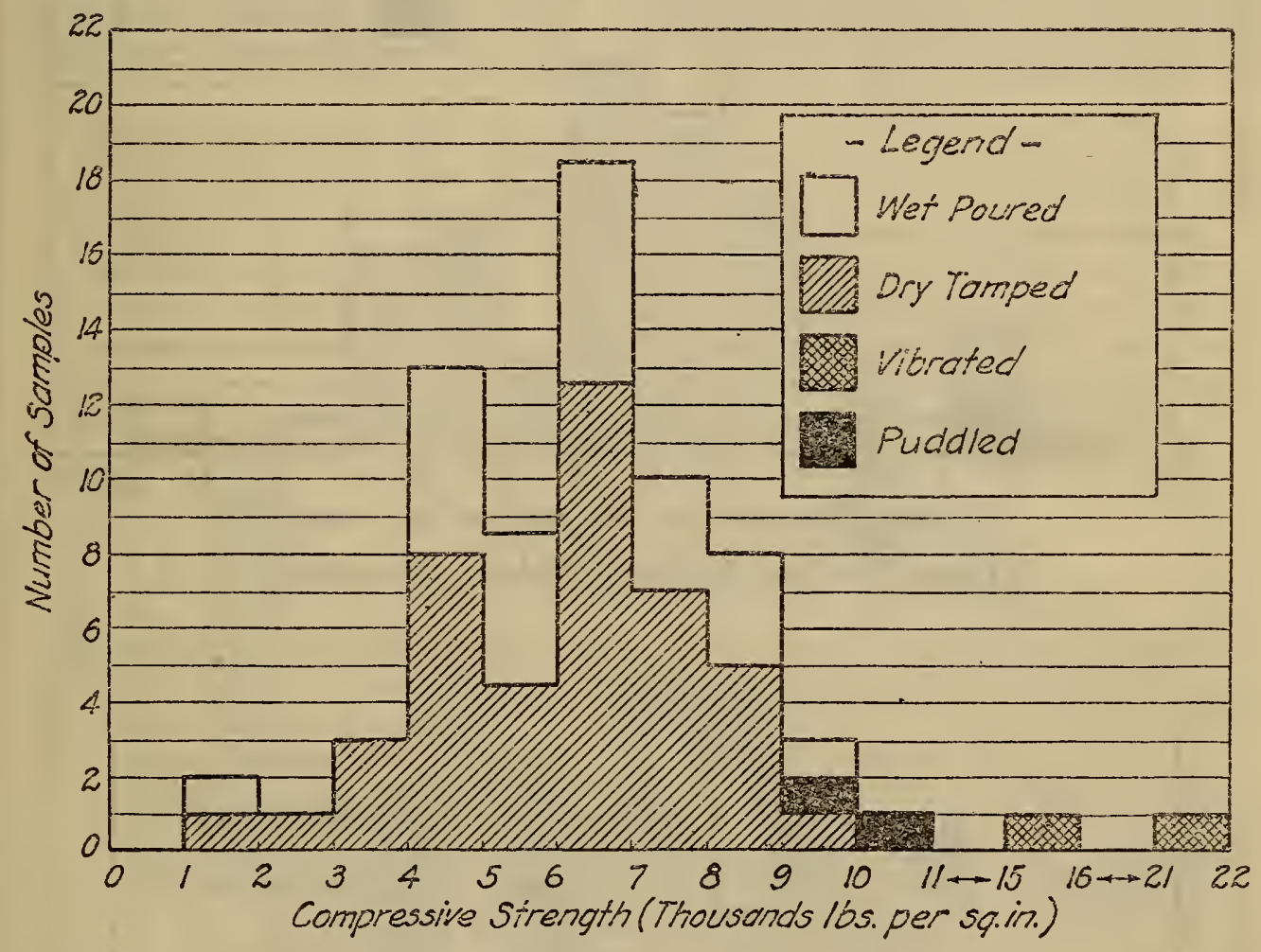

Figure 1.-Distribution of compressive strength of 2 by 2 inch cylinders

to area of cross section, were greater than the prism strengths. They varied from 1,550 to $21,720 \mathrm{lbs}$. $/$ in. $^{2}$, the distribution of the strengths being given in the histogram of Figure 1.

The modulus of ruptures varied from 220 to $1,640 \mathrm{lbs} . / \mathrm{in} .^{2}$, which is not as great a proportional range of variation as for the compression test results. This is to be expected from the results of flexural tests that have been made on concrete beams.

It is to be noted that the samples of concrete with the two highest compressive strengths were, respectively, fifth and thirteenth in order of modulus of rupture strength. This difference in order is probably due to the vibration method of fabrication of these specimens which causes "close packing" of the aggregate, markedly increasing the compressive strength but not increasing the cross bending strength by nearly so large a percentage. The distribution of the prism and cylinder compressive strengths (see fig. 1) and the cross bending strengths of the dry tamped specimens is very nearly the same as that of the wet poured specimens. 
The absorptions following drying at $105^{\circ}$ to $110^{\circ} \mathrm{C}$. exhibit the same wide variation as the strengths. The 2.0 per cent water absorp-

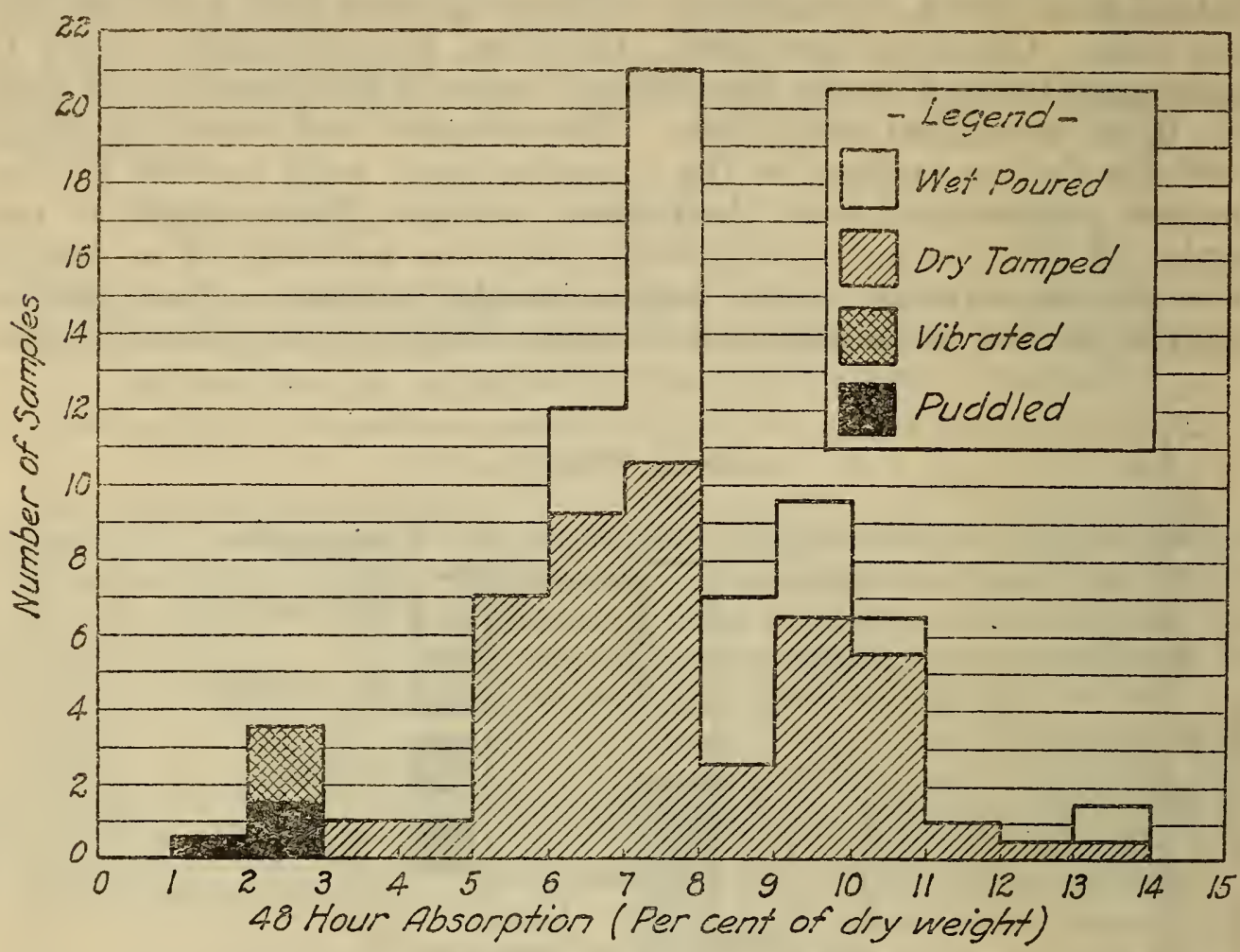

FIGURE 2.-Distribution of 48-hour absorptions

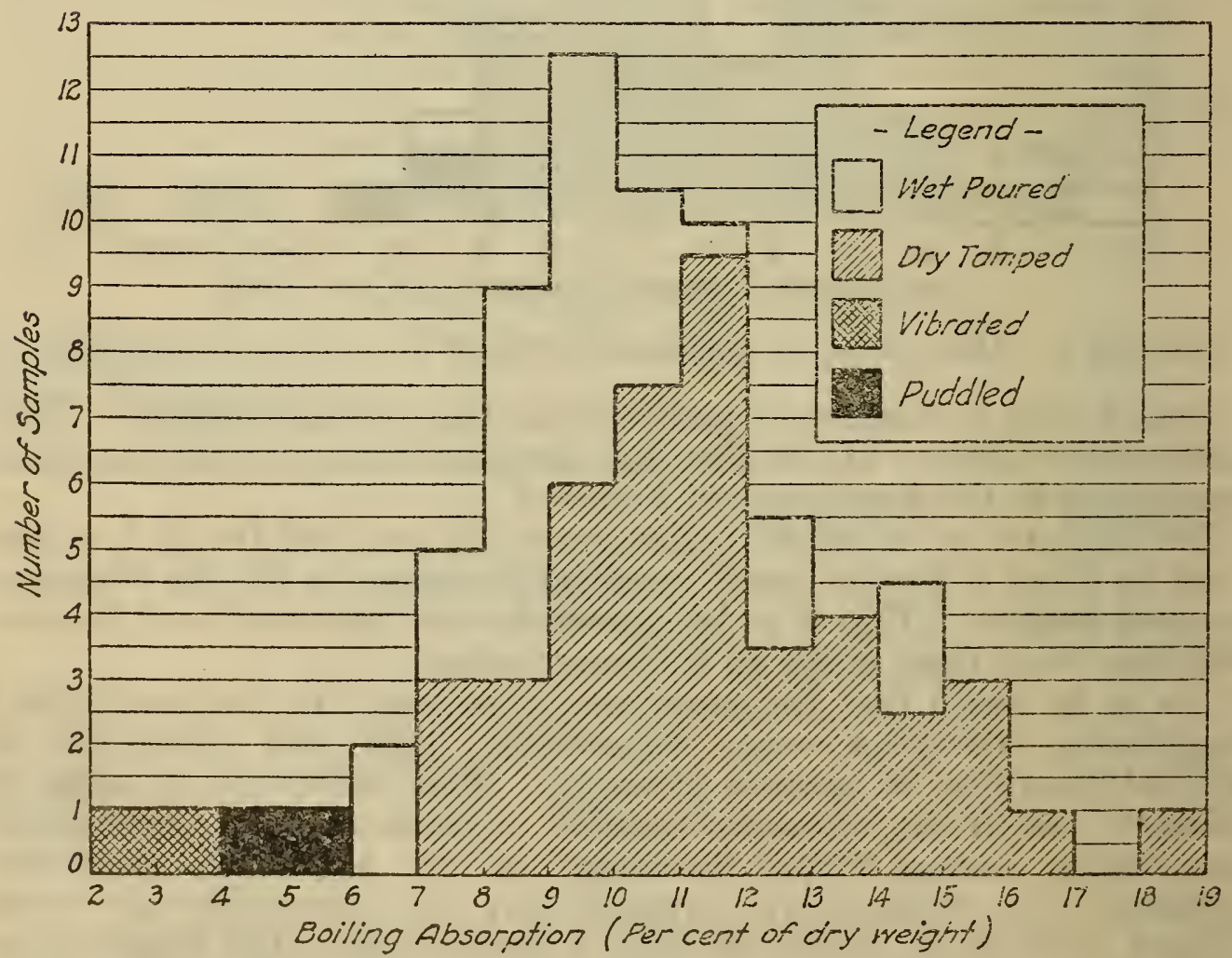

FrgURE 3.-Distribution of boiling absorptions

tion of specimen BG at 48 hours and the 2.5 per cent absorption of specimen BY after 48 hours in cold water and 5 hours in boiling 
water are unusually low values for concrete made with ordinary aggregate. The cold-water absorptions of the tamped specimens is in general lower than the absorption of the poured specimens. (See fig. 2.) In the boiling absorption, however, the tamped specimens average higher than the poured, thus reversing the order. (See fig. 3.) The strengths and absorptions are roughly related to each other, for, in general, the higher the strength the lower is the absorption.

Only 45 samples were dried at $65^{\circ} \mathrm{C}$. and boiled for five hours. Absorption values ranging from 3.0 to 17.2 per cent were obtained, and in every case the absorption was less than that obtained by drying at $105^{\circ}$ to $110^{\circ} \mathrm{C}$. followed by 48 -hour water immersion and subsequent 5 -hour boiling. The equivalent water absorptions in $300^{\circ}$ oil following a drying at $35^{\circ} \mathrm{C}$. were all lower than the water absorptions up to six hours. At 24 and 48 hours the oil absorption of one

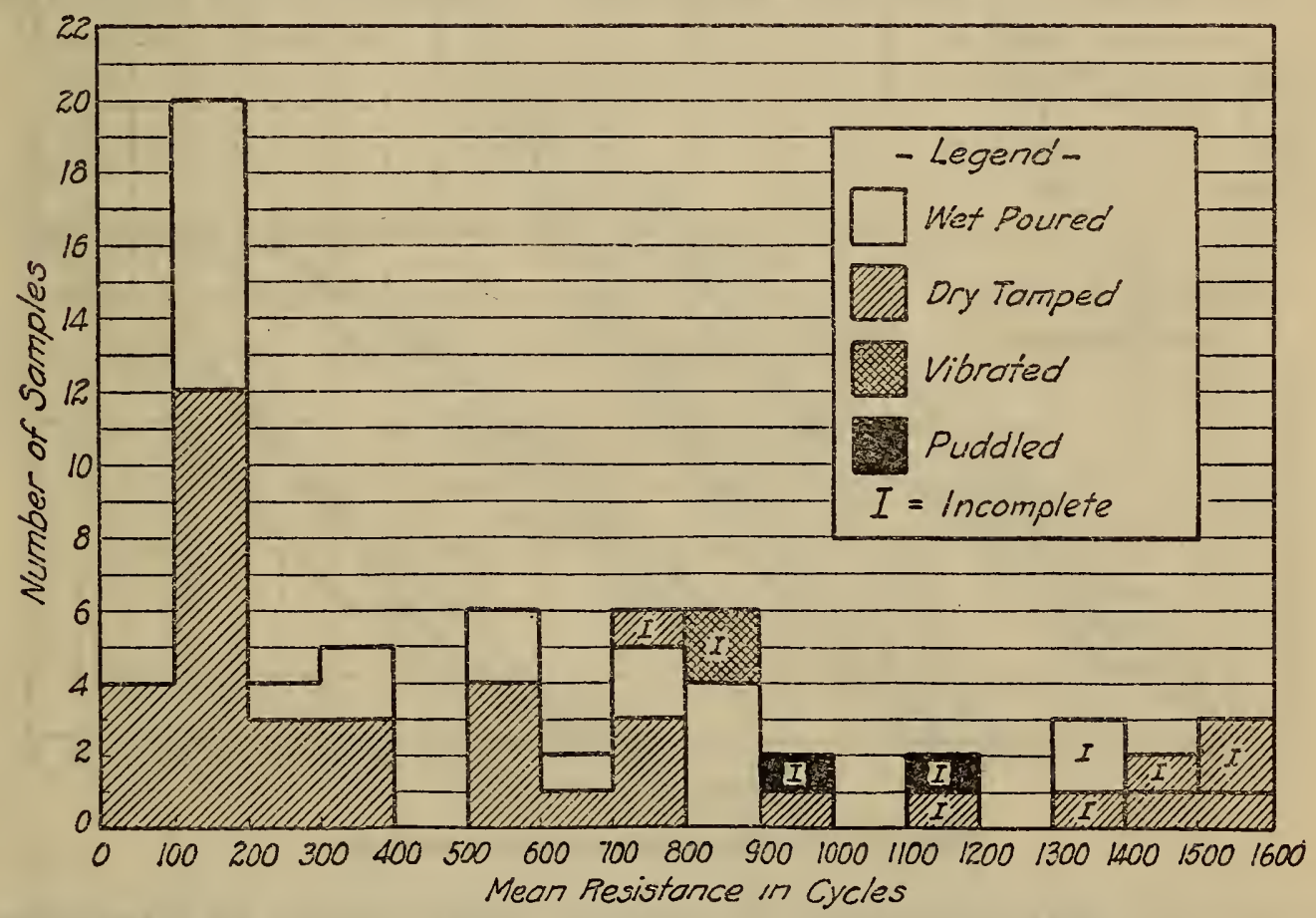

FIGURE 4.-Distribution of resistance to freezing and thawing

specimen (BF) was more than the water absorption at similar intervals, although the boiling absorption was greater than the oil absorption under vacuum. These special tests indicate that the absorption values include factors other than simple filling of the voids with water, since part of the water lost and regained is probably water of hydration. Furthermore, the values were in no better accord with the resistance to freezing and thawing than those obtained by the more commonly used methods.

The range in resistance to freezing and thawing is proportionately larger and even more remarkable than the range in the strengths and the absorptions. (See fig. 4.) Sample BM showed the least resistance, the first sign of disintegration being noted at the twentysecond cycle and complete disintegration occurring at the twentyfifth cycle. This sample had the lowest compressive and cross bending strengths and the highest absorption up to 48 hours, and would, a priori, be expected to have a low resistance. Sample $E$ was the 
most resistant, showing the first signs of disintegration at the one thousand four hundred and fiftieth cycle, but did not have outstanding physical characteristics that would indicate such a high resistance. It is to be noted that the wet-poured and dry-tamped specimens are equally distributed in their resistance to disintegration, and that the specimens made by puddling and by the vibration method are above the average resistance.

The properties of the two puddled concrete specimens, particularly the high strengths and the low absorptions, would indicate that they were made from a rich mix (as verified by the maker's statement of the proportions) with a moderate water content, and of a plastic consistency, very different from the consistencies used in the drytamp and wet-pour processes. It is probable that the consistency

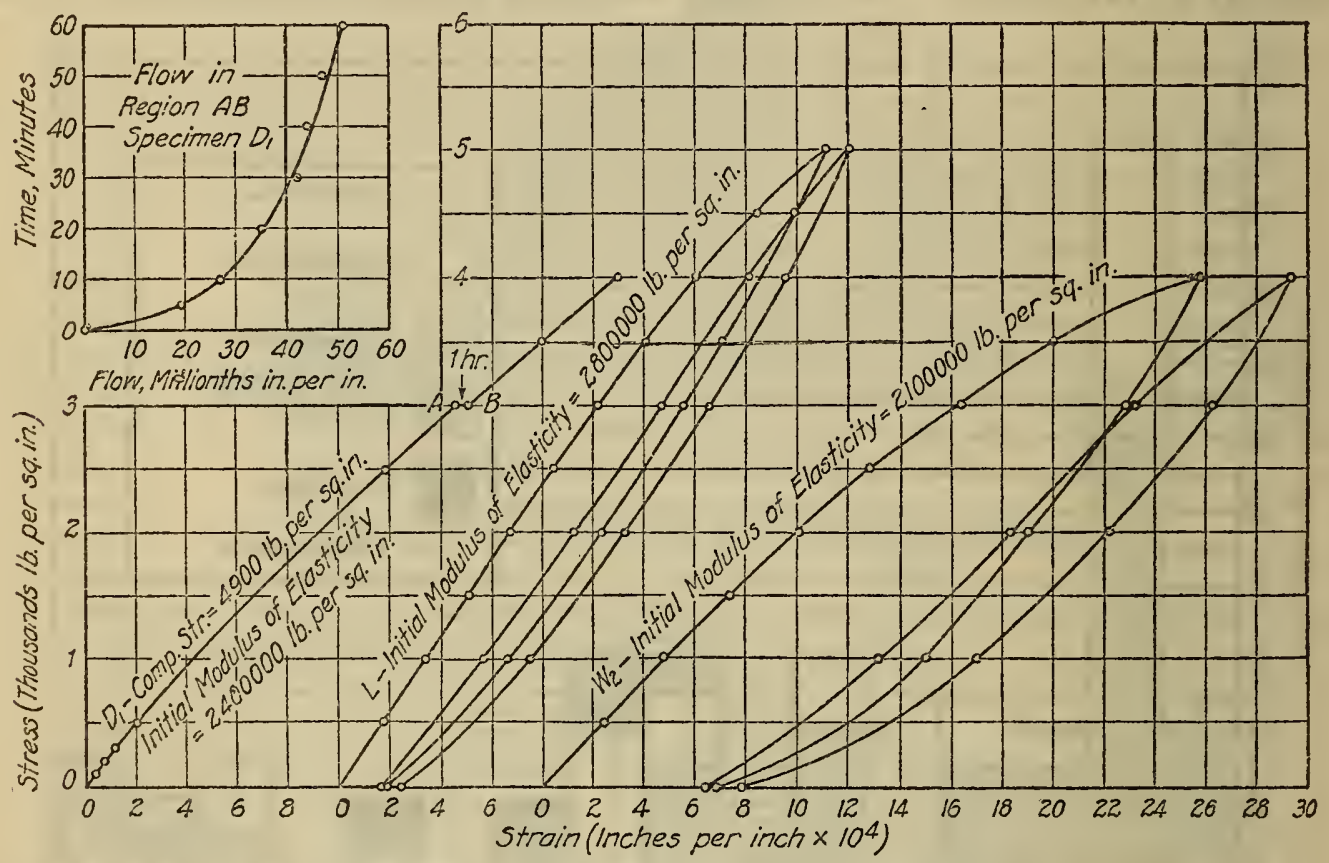

FIGURE 5.-Stress-strain-flow readings

was close to that at the point of minimum permeability as determined by Glanville. ${ }^{1}$

It was observed that none of the specimens used in the absorption or freezing and thawing tests showed any signs of staining or efflorescence.

Stress-strain measurements were made on 15 oven dried 2 by 2 inch prisms 4 inches high cut from 11 of the samples. Some of these results are shown in Figure 5 . The strain measurements were made with a Tuckermann gage on a 2-inch length and were carried close to the compressive strength of the material. The initial modulus of elasticity values ranged from 1.3 to 3.2 million pounds per square inch, values that are not divergent from those ordinarily to be expected from concrete.

Repeated loadings were made on most of the specimens, and on specimen $\mathrm{D}_{1}$ time flow measurements were made for one hour. The load on this specimen was maintained at $3,000 \mathrm{lbs}$./in..$^{2}$ or 61 per cent of the $4,900 \mathrm{lbs} . / \mathrm{in} .^{2}$ ultimate strength of the specimen. In an hour

1 Glanville, W. H., Building Research Technical Paper No. 3 of the Department of Scientific and Industrial Research, Great Britain. 
the measured flow was 0.00005 in./in. The repeated loading curves showed the usual hysteresis loops.

Although the strain readings that were made are of no direct importance in indicating the quality of the material to withstand weathering, they are of sufficient interest in themselves to warrant presentation here. The measurements are also interesting in showing the delicacy of the Tuckermann gage. To obtain the full advantage of the precision of this gage the readings should be made in a constant temperature room.

\section{THE CORRELATION OF RESISTANCE TO WEATHERING WITH OTHER PHYSICAL PROPERTIES}

The important physical property of cast stone is its resistance to destruction by weathering. The other physical properties are of

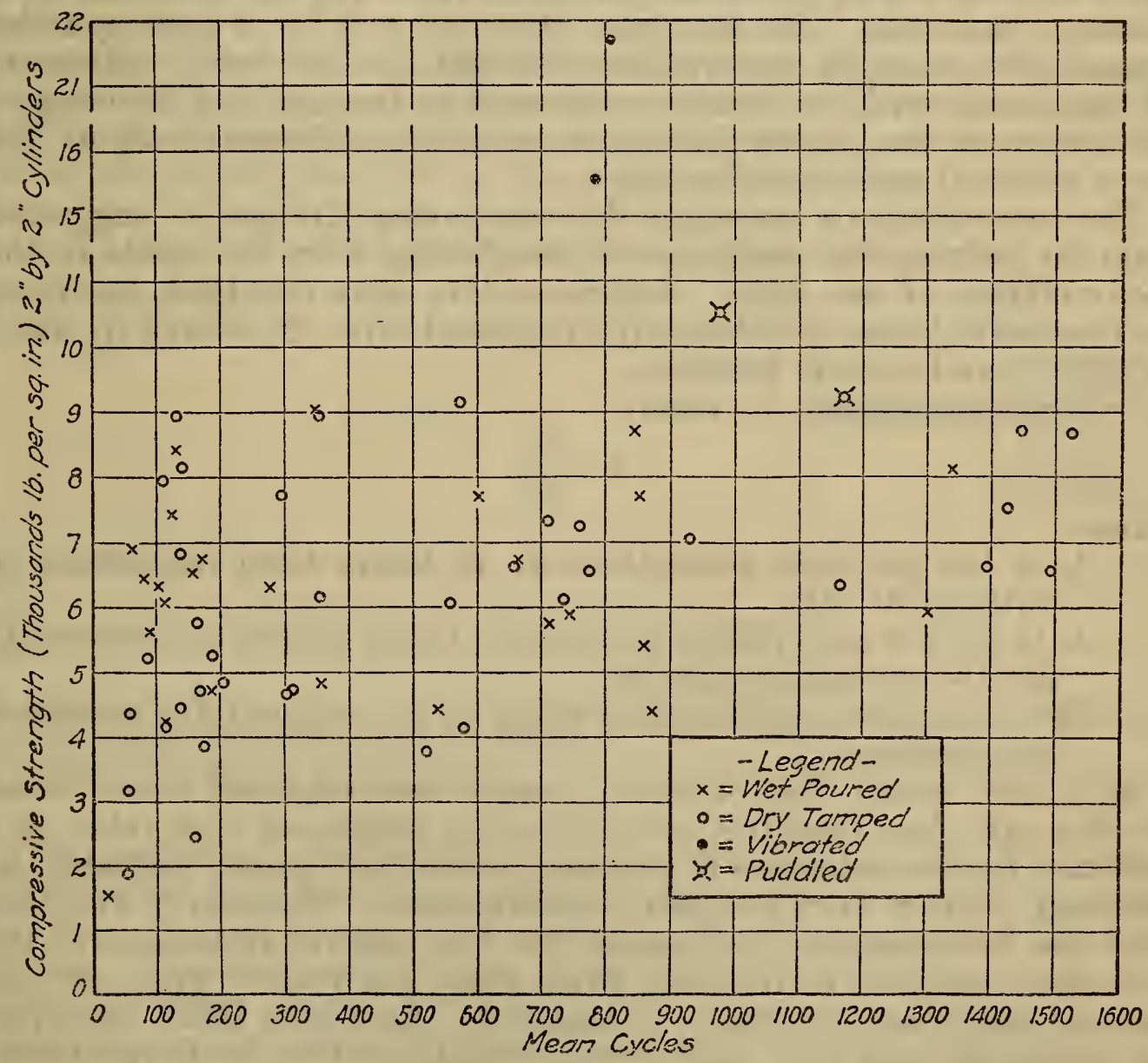

Figure 6.-Compressive strength compared to mean resistance to freezing

minor importance except for the possibility of their use in indicating this resistance. The effects of the freezing and thawing tests should not, a priori, be expected to be identical with the effects of outdoor exposure causing the disintegration that is known as weathering. Materials placed out of doors are subjected to natural weathering processes other than the freezing and thawings of entrained water. Alternate soaking and drying probably also produces disintegration. Large and fairly rapid changes in temperature, such as occur between days of strong sunshine and cool nights, are ascribed by geologists as 
the cause of the exfoliation of granite boulders. Crystallization of salts in the pores of materials may be an additional cause of disintegration. However, in lieu of any more satisfactory test and because actual weathering tests would require a minimum of several decades for the accumulation of satisfactory data, the freezing and thawing tests were accepted as a standard in the present analysis.

The half-hour and the 48-hour absorptions as well as the porosities show practically no correlation with resistance to destruction. The boiling absorption, that is, the absorption after 48 hours followed by 5 hours boiling, shows a slight trend of increasing resistance with decrease in absorption. There is a slightly better correlation between cylinder strength and resistance as shown in Figure 6 ; the correlation between prism strength and resistance is not superior to that shown in Figure 6. However, the correlation of any of the strengths, or of the boiling absorption, with the resistance to freezing is so low that these criteria are of no direct practical value for the selection of a resistant material. For example, although a 2 by 2 inch cylinder compressive strength requirement of $9,000 \mathrm{lbs}$./in. ${ }^{2}$ would eliminate all specimens with an average resistance to freezing and thawing of 150 cycles or less, it would at the same time eliminate all of the more resistant specimens but six.

The measurements necessary for computing Kreüger's ${ }^{2}$ suggested ratio for judging the resistance to weathering were not made in the accumulation of test data. Sufficient data were obtained, however, for the computation of Schurecht's proposed ratio $(S)$ offered by him ${ }^{3}$ as simpler and equally effective.

Schurecht proposed the ratio:

where

$$
S=\frac{A_{c}}{A_{b}}
$$

$A_{c}$ is the per cent absorption at 48 hours total immersion in water at $21^{\circ} \mathrm{C}$.

$A_{b}$ is the per cent absorption after 5 hours boiling subsequent to the 48-hour absorption $A_{c}$.

The absorption percentage is based on the original dry weight of the specimen.

Schurecht found that resistant ceramic materials all have values for this ratio less than 0.8 , and, therefore, suggested this value as a criterion for the selection of ceramic bodies that would probably be resistant. From even a cursory examination of the data it was seen that the $S$ values give no insight into the relative resistance of the cast-stone samples to freezing, even when the poured group or the tamped group are seperately considered. As shown later, however, the Schurecht ratio is of value when correlated with other properties of the cast stone.

All but four of the poured specimens have Schurecht ratios above 0.75 , and all but four of the tamped specimens had values below 0.8 . More than half of the wet poured specimens have values for $S$ that would indicate poor resistance while only three of the dry-tamped specimens have values of $S$ which indicate inferior quality. Nevertheless, as may be seen from Figure 4, the poured and tamped speci-

\footnotetext{
${ }^{2} \mathrm{H}$. Kreüger, Trans. of the Royal Swedish Inst, for Scientific and Industrial Research, Stockholm, No. $24 ; 1923$.

I. A. Palmer and J. V. Hall, Proc., A. S. T. M., vol. 30, Pt. II; 1930.
} 
mens were of approximately equal average resistance to freezing and thawing cycles.

The reader is referred to a paper entitled "The Selection of Durable Aggregate for Concrete," 4 for comments on Kreüger's and Schurecht's criteria as applied to stone and to slag of a size suitable for use as large aggregate in concrete. In that paper it was shown that these criteria are of no value in indicating the resistance of an aggregate to freezing and thawing tests. The porosity of the aggregates was, however, much lower than that of the greater part of the cast-stone specimens included in the present tests.

Portions of the 1 by 1 inch prisms of five samples were ground down until each weighed approximately $150 \mathrm{~g}$. They were dried at $105^{\circ}$ to $110^{\circ} \mathrm{C}$. to constant weight and the 48 -hour $21^{\circ} \mathrm{C}$. water absorption determined. The specimens were then subjected to freezing and thawing cycles. Weighings of the specimens were made up to the thirty-fifth cycle. It was found that the weight of all specimens increased as the cycles were continued. Table 2 gives a synopsis of the results obtained. One specimen (AU) with an original Schurecht ratio of unity absorbed still more water when frozen and thawed. Specimen $\mathrm{AC}$ reached the boiling absorption at the twenty-first cycle, $\mathrm{BF}$ at the eighth, and $\mathrm{BG}$ at the twenty-sixth cycle.

TABLE 2.-Increase in absorbed water due to freezing cycles

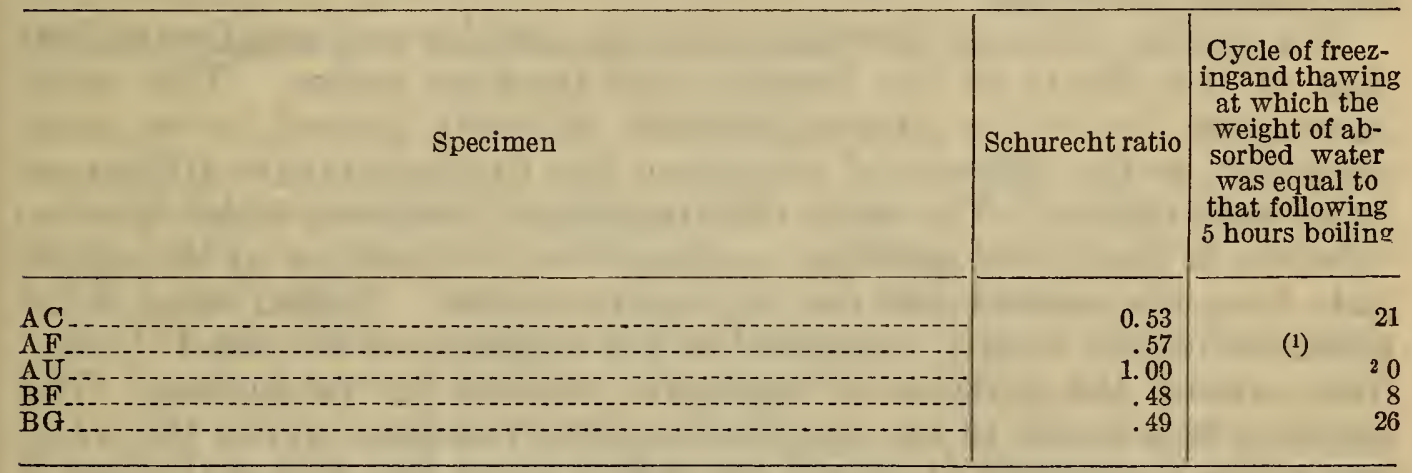

1 At the end of the thirty-fifth cycle specimen AF had gained 0.84 of the weight of water that would have been present in the voids after 5 hours of boiling.

2 This specimen continued to absorb water slowly, and at the thirty-fifth cycle bad absorbed 7 per cent more water than it contained after 5 hours boiling.

No specimen tested failed in the first freezing, the least resistant specimen showing first signs of failure in 22 cycles, the most resistant showing first signs at 1,450 cycles. The Schurecht or Kreüger criteria, however, indicate the potential destructive action of the entrained water during the first cycle. As shown in Table 2, the entrained water constantly increases, and if the $S$ or $K$ ratios be applied, they must be determined for each increasing cycle. The problem is further complicated in that the relative amounts of the entrained water that is mechanically held and that is chemically combined is unknown.

Since the resistance to disintegration by freezing and thawing has been shown to be practically independent of the absorption and therefore the porosity, we may conclude that the destruction is probably not solely due to the internal pressure of the contained ice. It should

1 Rock Products; Aug. 1, 1931.

$84614-31-5$ 
be noted carefully, however, that the stresses caused in the material by the pressure of the ice, will possibly depend on the pore shape as well as the relative pore space. It may well be that Kreüger's ratio or some other absorption measurement may give an empirical indication of this shape and so prove of value in indicating the resistance to freezing and thawing tests.

The simpler physical tests having failed to give a definite indication of the resistance to destruction by freezing, the cast-stone samples were carefully examined for structure and for mineral composition of the aggregates. The type of aggregate or the combination of aggregates present in the test specimens apparently has no important influence on the resistance. For example, samples A, C, D, and E had very similar values for compressive strength, absorption and Schurecht's ratio, and all but one had practically the same modulus of rupture. However, samples D and E were highly resistant, while $\mathrm{A}$ and $\mathrm{C}$ showed very low resistance. Sample E was fabricated by the dry-tamp process; the others were wet-poured. Samples C and $\mathrm{E}$, one poor, the other very good, had only one material, calcite, as aggregate. Samples $\mathrm{A}$ and $\mathrm{D}$ had calcite and slag as aggregate, yet in resistance to freezing and thawing one was poor, the other very good. The whole list of samples may be examined and it will be found, as with these four samples, that the materials made with any particular type of aggregate show no definite superiority in relation to the other samples.

The spalling of small particles from the surface was usually the first sign of the effects of the freezing and thawing cycles. This could have been due to the internal pressure of newly formed ice or, more probably, to the differential expansion due to temperature differences or to both effects. The main disintegration, however, which bore no relation to the initial spalling, consisted in a separation of the aggregate from the cement and fine aggregate mortar. Initial signs of the ultimate failure usually consisted in the appearance of raised "map" lines around the portions of aggregate exposed on the surface. The concrete was found to have separated along this line, and as the freezing cycles progressed, it would rise higher along one side of the line of separation than the other until eventually a portion on the higher side would separate completely from the remainder. Examination of such a piece and the surfaces of separation indicated that the separation was accompanied by a destruction of the bond of the mortar to the aggregates.

\section{SPECIFICATION REQUIREMENTS}

The time required to determine weathering resistance by repeated freezing and thawing is so great that it is not practicable to use this test as a specification requirement. Simpler physical tests which can be made within a week must be used. Unfortunately such tests show individually a low correlation with the results of the cyclic freezing and thawing tests. Consequently, the specification must be based upon several requirements, which together will exclude a large proportion, if not all, of the materials having a low weathering resistance.

It may happen that some samples which have shown satisfactory weathering qualities (as determined by the freezing and thawing test) may also be excluded. This is unfortunate, but the exclusion of poor material is the fundamental objective of the specification. 
The requirement of a minimum compressive strength of 5,000 lbs./in. ${ }^{2}$, of a maximum 48-hour absorption of 8 per cent, and of a maximum boiling absorption (48 hours soaking at room temperature followed by five hours boiling) of 11 per cent eliminated a large number of the specimens with poor weathering qualities.

While seeking an additional criterion of rejection, it was noted that a large portion of the poor samples that had not been rejected had Schurecht ratios below 0.6 or above 0.9 . It was also noted that most of the good samples in this category had low absorptions. The requirements of a Schurecht ratio of not less than 0.6 nor more than 0.9 was, therefore, added with the condition that it be applied only to those specimens whose boiling absorption was more than 6 per cent. The use of a lower limit for the Schurecht ratio has no theoretical foundation, but the results of these and other tests have shown that neither does an upper limit apply theoretically. Both were used solely because they were the only criteria found for separating a number of the specimens of good quality from those of poor quality that could be differentiated by no other means.

The specification as written eliminated all specimens (12) showing a weathering resistance of less than 113 mean weathering cycles, and all but two of the specimens (28) showing a weathering resistance less than 280 cycles. On the other hand, 21 specimens with a resistance of 300 cycles or over were excluded. Of the 68 specimens upon which all specification tests were made 19 met the requirements of the specification and 49 were rejected.

\section{SUMMARY}

1. The compressive strength of the 2 by 2 inch cylinders varied from 1,550 to $21,720 \mathrm{lbs}$./in. ${ }^{2}$; the compressive strengths of 1 by 1 by 2 inch prisms varied from 1,300 to $15,780 \mathrm{lbs}$./in. ${ }^{2}$

2 . The modulus of rupture determined on 1 by 1 by 8 inch bars on a 6 -inch span varied from 220 to $1,640 \mathrm{lbs} . /$ in. $^{2}$

3 . The 48-hour absorption in water at room temperature varied from 2.0 to 13.1 per cent of the dry weight, and after then boiling the specimens for five hours the absorptions ranged from 2.5 to 18.2 per cent.

4. There was no marked difference in the distribution of the strengths, the $21^{\circ} \mathrm{C}$. absorptions, or the resistance to destruction by freezing and thawing between the specimens made by the wet-cast and those made by the dry-tamped process. The boiling absorption of the dry-tamped specimens averaged higher than those of the wetcast specimens.

5. The two samples made by the vibration process were very high in compressive strength and above the average in cross-bending strength. The absorptions were much below the average, the resistances to freezing and thawing above the average.

6. The two samples made by puddling possessed the highest crossbending strengths and, other than the vibrated specimens, had the highest compressive strengths. Like the vibrated specimens, the absorptions were very low, and the resistance to freezing and thawing above the average.

7. The Schurecht ratios of the dry tamped specimens were almost all lower than those of the poured specimens. The Schurecht ratio 
in itself gave no indication of the quality of the materials for resistance to disintegration, but the far greater portion of these specimens with an absorption due to five hours boiling of more than 6 per cent and with a Schurecht ratio higher than 0.9 or lower than 0.6 , were of poor resistance.

8. Repeated freezing and thawing in which the specimen is constantly in contact with water results in the absorption of more and more water. The specimens within a short time, therefore, are all thoroughly saturated with water and the internal stresses produced by the cycles from this point of saturation onward must be independent of the initial Schurecht or Kreüger ratio.

9. There is not sufficient correlation of the resistance to freezing and thawing of the specimens with their strength and porosity to indicate that failure is due in any large measure to destruction by internal ice pressure.

\section{ACKNOWLEDGMENT}

The authors desire to express their appreciation of the assistance of Ward Pigman for identification of the mineral composition of the aggregates and other assistance in the preparation of the paper.

Washington, April 15, 1931. 